\title{
Reduction of operator radiation exposure using a passive robotic device during fluoroscopy-guided arterial puncture: an experimental study in a swine model
}

\author{
Muhammad Umair Ahmad Khan ${ }^{1 \dagger}$, Chang-Hwan Yoon ${ }^{2+}$ and Byung-Ju $\mathrm{Yi}^{3^{*}}$ (i)
}

\begin{abstract}
Background: Vascular interventions imply radiation exposure to the operating physician (OP). To reduce radiation exposure, we propose a novel passive robotic device for fluoroscopy-guided arterial puncturing.

Methods: X-ray dose rates were measured for a total of 30 fluoroscopy-guided puncture femoral arteries in 15 pigs. Fifteen punctures were performed with the device while the other 15 were performed without the device by an interventional cardiologist with 10 years of experience. Parametric $t$ test was used.

Results: The success rate with the device was $100 \%$. Overall, the OP received more radiation $(0.41 \mathrm{mSv} / \mathrm{h})$ as compared to the assistant $(0.06 \mathrm{mSv} / \mathrm{h})(p<0.001)$ and, amongst OP's body parts, hands received more radiation than other body parts $(p<0.001)$. The radiation dose rate to the OP's hands during arterial puncturing performed manually without the device was $0.95 \pm 0.25 \mathrm{mSv} / \mathrm{h}$ whereas it was $0.14 \pm 0.006 \mathrm{mSv} / \mathrm{h}$ using the device, resulting in an $85 \%$ reduction $(p<0.001)$. For the head, the dose was reduced from $0.16 \mathrm{mSv} / \mathrm{h}$ to $0.08 \mathrm{mSv} / \mathrm{h}$ ( $50 \%$ reduction, $p<0.001$ ), and for the dominant arm, from $0.12 \mathrm{mSv} / \mathrm{h}$ to $0.07 \mathrm{mSv} / \mathrm{h}$ ( $42 \%$ reduction, $p<0.001$ ). The fluoroscopy time was reduced from $4.5 \pm 0.15 \mathrm{~min}$ to $4.3 \pm 0.11 \mathrm{~min}$ device $(p=0.002)$.
\end{abstract}

Conclusions: In a swine model, fluoroscopy time and radiation exposure for the OP puncturing femoral artery were significantly reduced by using the passive robotic device.

Keywords: Fluoroscopy, Occupational exposure, Radiation exposure, Radiation protection, Radiology (interventional)

\section{Key points}

- A passive robotic device for arterial puncturing was developed.

- Using the robotic device, the mean fluoroscopy time was significantly reduced from 4.5 to $4.3 \mathrm{~min}$.

- Using the robotic device, the mean radiation dose rate to the hands of the operating physician was significantly reduced from $0.95 \mathrm{mSv} / \mathrm{h}$ to $0.14 \mathrm{mSv} / \mathrm{h}(-85 \%)$.

\footnotetext{
* Correspondence: bj@hanyang.ac.kr

${ }^{\dagger}$ Muhammad Umair Ahmad Khan and Chang-Hwan Yoon contributed equally to this work.

${ }^{3}$ Department of Electronic Systems Engineering, Hanyang University, 55 Hanyangdeahak-ro, Sangnok-gu, Ansan 15588, Gyeonggi-do, South Korea Full list of author information is available at the end of the article
}

- Using the robotic device, the mean radiation dose rate to the head of the operating physician was significantly reduced from $0.16 \mathrm{mSv} / \mathrm{h}$ to $0.08 \mathrm{mSv} / \mathrm{h}(-50 \%)$.

- Using the robotic device, the mean radiation dose rate to the dominant arm of the operating physician was significantly reduced from $0.12 \mathrm{mSv} / \mathrm{h}$ to 0.05 $\mathrm{mSv} / \mathrm{h}(-42 \%)$.

\section{Background}

Fluoroscopy-guided puncture is commonly performed for precisely targeting and placing needles and guidewires during different interventional procedures. The use of fluoroscopy results in non-negligible radiation exposure to the operating physician [1-4]. The effective dose range varied from microSievert to $\mathrm{mSv}$ per procedure. Radiation doses to the patients, operators, and the assistants had 
been investigated in different studies [5-9]; other studies specifically investigated the radiation dose to the hands of the operating physician [10-14].

This is a relevant occupational issue when we take in consideration that specialised physicians, in particular interventional radiologists, perform fluoroscopy-guided interventions on a daily basis. The dose limit for various organs was defined by the International Commission on Radiological Protection [15]. In the case of occupational exposure, the average value of effective dose limit is 20 $\mathrm{mSv} /$ year, with an absolute limit of $100 \mathrm{mSv}$ over 5 years.

Radiation dose received by the operating physician during fluoroscopy depends upon various factors such as fluoroscopy time, protective shielding against radiation, closeness to the $\mathrm{x}$-ray source, position of the $\mathrm{x}$-ray source, and awareness about radiation exposure. In particular, large variation in the effective dose received by the operating physician when performing arterial puncturing is strongly depending on closeness to the $x$-ray source.

Passive robots referred to the type of robots that do not use actuators for the motion, with all the joints moved manually. In the medical field, passive robots helped the physician to manually operate a robot by himself rather than operating the motors by the help of joysticks as in the case of active robots. Passive robotics could be a valuable tool for fluoroscopy-guided arterial puncture because it enabled a stable needle control by the operating physician at greater distance from the $\mathrm{x}$-ray source.

Thus, the main aim of this study was to compare radiation doses to different body regions, while performing arterial puncture with and without a passive robotic device.

\section{Methods}

This study was approved by the Animal Ethical Committee of Seoul National University Bundang Hospital (code of approval: BA1708-230/075-01) and was performed in accordance with the Guide for the Care and Use of Laboratory Animals from the Institute of Laboratory Animals Resources [16].

\section{Design of the passive robot}

The robotic mechanism consisted of a 7-degree of freedom (DoF) passive arm and 1-DoF needle holding assembly as shown in Fig. 1a. The three-dimensional model of the robotic mechanism is shown in Fig. 1b. We employed a 7-DoF commercially available passive arm (MA60003, NOGA Engineering \& Technology, Nazareth, Israel). All 7 DoF of the passive arm could be locked at once by locking the knob.

To operate the device without exposing the physician's hand, a needle holding assembly was designed. The needle holding assembly consisted of a platform, a linear stage for needle insertion, a needle holding aluminium rod, and a roller driving the needle. This device enabled the physician to move the needle easily without exposing herself/ himself to $\mathrm{x}$-rays. After positioning the needle to the target blood vessel, the roller could be operated at different configurations to give the physician ease in manoeuvring the needle tip.

The linear stage provided forward and backward motion. Needle holding aluminium rod was attached to the linear stage. The hub of the needle was attached to the needle holder assembly by bolts in such a way that the needle remained fixed to the holder during the interaction of the needle with the skin. The needle holder was designed in such a way so that different types of needles can be attached to the holder. Two sideways bolts for needle attachment also helped the physician in accurately aligning the needle to the targeted blood vessel during fluoroscopy-guided arterial puncturing. The third bolt tightened the hub of the needle firmly. For the insertion of a guidewire tool in the hub of the needle, a small groove had been carved out inside the needle holder assembly

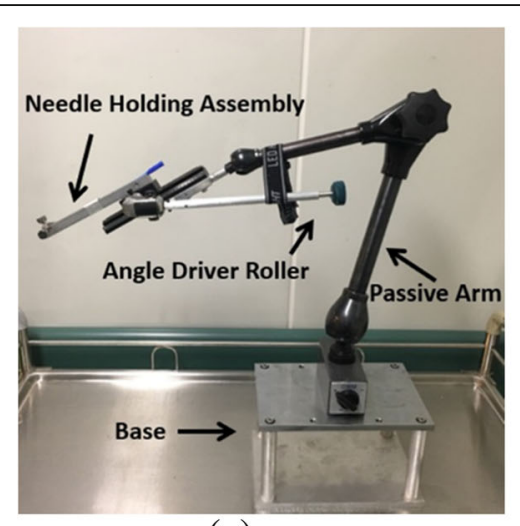

(a)

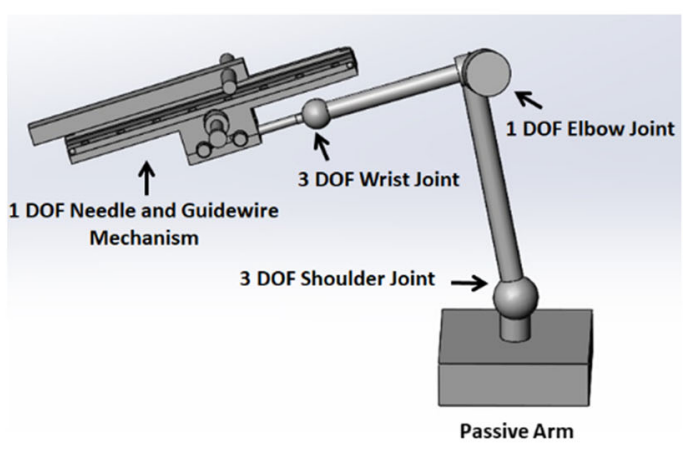

(b)

Fig. 1 Passive arm and needle holding assembly. a Seven-degree of freedom (DoF) passive arm with 1-DoF needle holding assembly. Long angle driver roller allows the physician to perform arterial puncturing away from the x-ray source. Base could be easily fixed on the patient bed. $\mathbf{b}$ Three-dimensional model of the passive arm and needle holding assembly 
(Fig. 2). The guidewire was inserted inside the tool. The guidewire insertion tool was designed in such a manner that it would not allow the flexible end of the guidewire to bend. Buckling of the flexible tip of the guidewire could be avoided if the tip of the guidewire insertion tool was inserted properly into the hub of the needle. When the needle was inserted to the targeted blood vessel, blood came out from the hub, indicating the proper insertion of the needle tip. After the insertion of the guidewire, the needle could be removed easily by retracting the 7-DoF passive articulated arm. The base of the device was designed in such a way that it could be easily attached to the patient's bed with the help of a clamp. It could also be attached to the table next to the bed according to the ease of the physician.

Figure 3a shows the position of the operator's hand without the device while Fig. 3b shows the position of the operator's hand with the device. The use of the device allowed the operator to keep his hand away from the $\mathrm{x}$-ray source.

\section{Animal preparation}

The day before the experiment, male crossbred swine ( $n$ = 15; weight, from 17 to $35 \mathrm{~kg}$ ) were fed with aspirin (300 mg) and clopidogrel (300 mg). On the experiment day, the swine were premedicated with atropine sulphate $(0.05 \mathrm{mg} / \mathrm{kg}$, intramuscularly) and subsequently anaesthetised with Zoletil $(5 \mathrm{mg} / \mathrm{kg})$ and Xylazine $(4.4 \mathrm{mg} / \mathrm{kg})$ intramuscularly, intubated, and ventilated with room air and isoflurane. We inserted a 6-Fr sheath via the right carotid artery by ultrasound-guided puncture. The animals received heparin $(5000 \mathrm{U})$ intravenously prior to femoral artery digital subtraction angiography.

\section{Fluoroscopy-guided femoral arterial puncture}

A total of 30 fluoroscopy-guided punctures were performed, 15 using the robotic device and 15 without the device by an interventional cardiologist with a 10-year experience, targeting both femoral arteries in the 15 pigs.
The mobile fluoroscopy system was Philips BV Pulsera (Philips Medical Systems, Bothell, USA). We selected both femoral arteries with a diagnostic catheter (Judkins right 4, Gifu, Japan) via the right carotid artery and performed angiography to guide the femoral puncture using the Seldinger technique.

Details on the use of the passive robotic device have been described in the previous section describing the design of the passive robot.

\section{Measurement of radiation exposure}

The radiation dose was measured using dosimeters that were attached to the different unprotected parts of the operating physician (Ray 3000, Kedian, Jining, China), and was used to measure the radiation. The dosimeters were attached to the dominant hand, dominant arm, and head of both the operating physician and the assistant animal technician (nurse). In this study, all the dose rates were measured in $\mathrm{mSv}$ per hour.

Two parameters were selected to analyse the effectiveness of the device: the success rate of the insertion procedure and the complication level, the latter including three sub-categories which were haematoma (collection of blood outside the vessel); dissection (tear of the vessel wall, which allows blood to separate the wall layers); and occlusion (a blockage of the vessel, usually by a clot or a severe dissection).

\section{Statistical analysis}

Continuous variables were described as mean \pm standard deviation (SD), taking into consideration their normal or near normal distribution, confirmed by Shapiro-Wilk test $(p=0.9003)$. As a consequence, the comparison between the means of the two groups was evaluated by Student's $t$ test. A two-sided probability value of $<0.05$ was considered indicative of a statistically significant difference. The success rates were presented as percentages with their $95 \%$ confidence intervals, calculated according

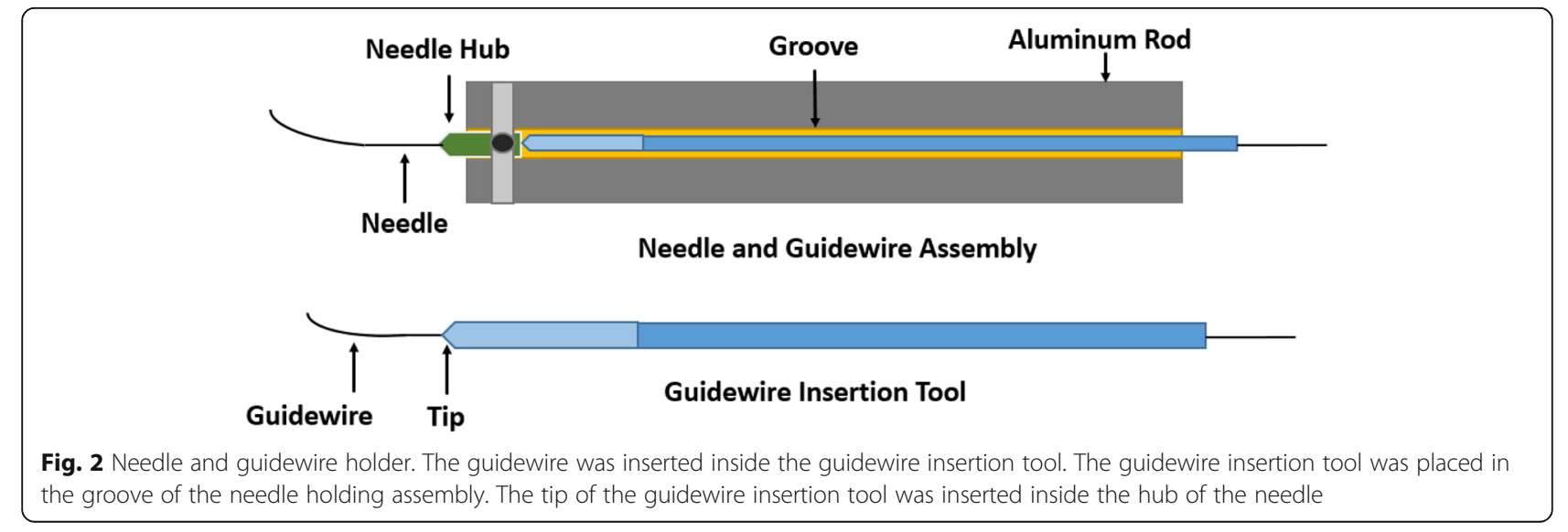




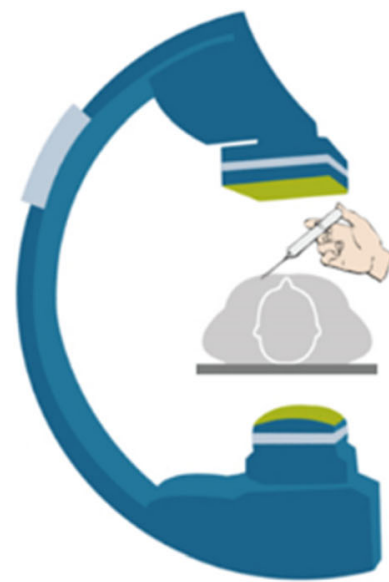

(a)

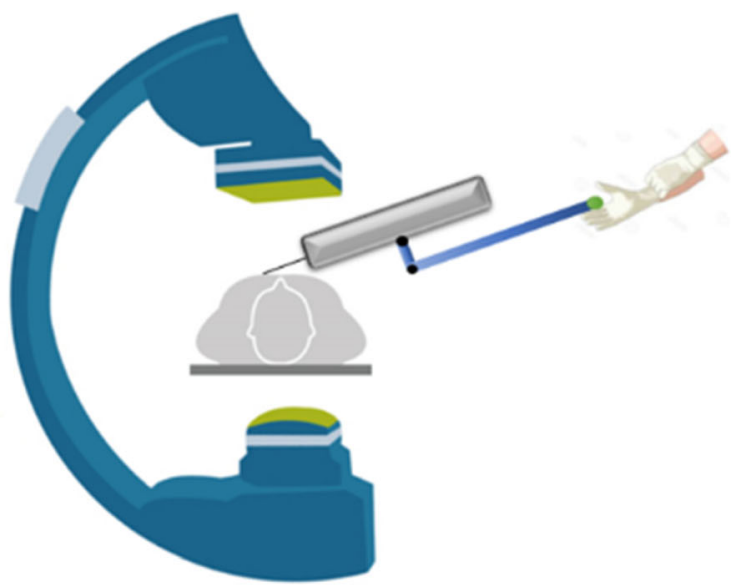

(b)

Fig. 3 Position of the hand with and without the device. On the left (a), without the device, the physician's hand is directly exposed to radiation. On the right (b), with the device, the physician's hand can stay away from the x-ray source

to the binomial distribution. Statistical analysis was performed using R program version 3.1.0.

\section{Results}

Table 1 shows mean radiation dose rates for the arterial puncturing procedures performed by the operating physicians with and without the device. The maximum radiation exposure was measured on the dominant hand without using the device because the hands were directly exposed to radiation. The mean radiation dose rates for the dominant hand of the operating physician during arterial puncturing manually without any device were 0.95 $\mathrm{mSv} / \mathrm{h}$. Other unprotected parts like the head and arms were also exposed, and their dose rate was significantly $(p<0.001)$ lower as compared to hands.

The mean radiation dose rates for the dominant hand of the physician during arterial puncturing with the device were $0.14 \mathrm{mSv} / \mathrm{h}$. With the device, an $85 \%$ reduction in the operating physician's hand exposure was observed. In the case of the head and arm, mean dose rates were

Table 1 Radiation dose rate (mSv/hour) for the operating physician with and without the passive robotic device

\begin{tabular}{llll}
\hline & $\begin{array}{l}\text { Dominant } \\
\text { hand } \\
(n=15)\end{array}$ & $\begin{array}{l}\text { Head } \\
(n=15)\end{array}$ & $\begin{array}{l}\text { Dominant } \\
\text { arm } \\
(n=15)\end{array}$ \\
\hline $\begin{array}{l}\text { Dose rate without the device } \\
\text { (mean } \pm \text { SD) }\end{array}$ & $0.95 \pm 0.25$ & $\begin{array}{l}0.16 \pm \\
0.02\end{array}$ & $0.12 \pm 0.02$ \\
$\begin{array}{llll}\text { Dose rate with the device (mean } \\
\pm \text { SD) }\end{array}$ & $0.14 \pm 0.06$ & $0.08 \pm$ & $0.07 \pm 0.01$ \\
$p$ value & $<0.001$ & $<01$ & \\
Relative decrease & -85.2 & -50.0 & -41.6 \\
\hline
\end{tabular}

SD standard deviation reduced from $0.16 \mathrm{mSv} / \mathrm{h}$ to $0.08 \mathrm{mSv} / \mathrm{h}$ and $0.12 \mathrm{mSv} / \mathrm{h}$ to $0.07 \mathrm{mSv} / \mathrm{h}$, respectively (see Table 1 ).

Table 2 shows the results concerning efficacy and safety measurements. The success rate of performing arterial puncturing was $15 / 15$ (100\%, 95\% CI $0.78-1.00)$ both using or not using the robotic device. The mean exposure time with the device had been reduced to $4.3 \mathrm{~min}$ while without the device, it was $4.5 \mathrm{~min}$. In this study, two dissections and two haematomas occurred without the device while two dissections occurred when the physician performed arterial puncturing using the device.

Table 3 shows radiation dose rates for the assistant helping the operating physician: the mean radiation exposure was significantly lower than that of the operating physician for both cases when the physician performs puncturing procedures with or without the device $(p=$ 0.003 and $p<0.001$, respectively). Figure 4 shows the mean radiation exposure rate $(\mathrm{mSv}$ per hour) of the dominant hand. With the help of the device, the physician would get almost the same amount of radiation dose rate as that of the assistant.

Table 2 Fluoroscopy time, success rate, and complications with and without the passive robotic device

\begin{tabular}{lll} 
& Without device $(n=$ & With device $(n=15)$ \\
& $15)$ & \\
\hline $\begin{array}{l}\text { Fluoroscopy time (min, } \\
\text { mean } \pm \text { SD) }\end{array}$ & $4.5 \pm 0.15^{*}$ & $4.3 \pm 0.11^{*}$ \\
Success rate & $15 / 15(100 \%, 95 \% \mathrm{Cl}$ & $15 / 15(100 \%, 95 \% \mathrm{Cl}$ \\
& $0.78-1.00)$ & $0.78-1.00)$ \\
Complications & 2 haematomas & 2 dissections \\
& 2 dissections & \\
\hline
\end{tabular}

$S D$ standard deviation, $\mathrm{Cl}$ confidence interval ${ }^{*} p=0.002$ 
Table 3 Radiation dose rate ( $\mathrm{mSv} / \mathrm{hour}$ ) for the assistant with and without the passive robotic device

\begin{tabular}{llll}
\hline Location of dosimeter & Dose rate with the device $($ mean $\pm S D, n=15)$ & Dose rate without the device $(m e a n \pm S D, n=15)$ & $p$ value \\
\hline Dominant hand & $0.08 \pm 0.02$ & $0.09 \pm 0.01$ & 0.042 \\
Head & $0.08 \pm 0.01$ & $0.09 \pm 0.01$ & 0.021 \\
Dominant arm & $0.03 \pm 0.01$ & $0.04 \pm 0.01$ & 0.019 \\
\hline
\end{tabular}

$S D$ standard deviation

\section{Discussion}

The goal of the study was to compare the $\mathrm{x}$-ray dose rates for the operating physician and the assistant when performing fluoroscopy-guided arterial puncturing with or without a passive robotic device. It was observed that the operating physician was significantly more exposed to radiation as compared to the assistant. Amongst the body parts of the operating physician, the hands received significantly more radiation as compared to the head and arms. With the use of passive robotic device, an $85 \%$ decrease in radiation exposure rate of the hands was observed for the operating physician. The success rate of performing the arterial puncturing with the device was $100 \%(n=15)$. The mean fluoroscopy time was significantly $(p=0.002)$ reduced from $4 \mathrm{~min}$ and $30 \mathrm{~s}$ without the device to $4 \mathrm{~min}$ and $18 \mathrm{~s}$ with the device.

Two dissections when using the device while two dissections and two haematomas occurred when not using the device. Of note, the occurrence of complications as a consequence of arterial puncturing in humans has been reported to be very low, i.e. less than $0.5 \%$ [17]. However, dissections and haematomas occur more frequently in animal models due to smaller arterial size and higher susceptibility of the arterial wall to complications.

We observed that the skill of operating the passive robotic device played an important role in the reduction of mean fluoroscopic exposure time. Initially, the operating physician took longer time to perform arterial puncturing using the device, but as he had developed the skill of operating the device, the mean fluoroscopic exposure time had been reduced and it took the physician three experiments to become familiar with the use of the device.

When the operating physician performed the arterial puncturing using the robotic device, the hand of the physician remained far from the x-ray source. As a result, the radiation exposure to hands was significantly reduced.

Physicians utilise different ways to protect themselves from ionising radiation either by wearing thyroid collar and lead apron or by optimising the use of fluoroscopic devices and, in some cases, proper positioning of $\mathrm{x}$-ray source and operating fluoroscopic devices in pulsed mode [18-20]. However, the physicians and assistants are still

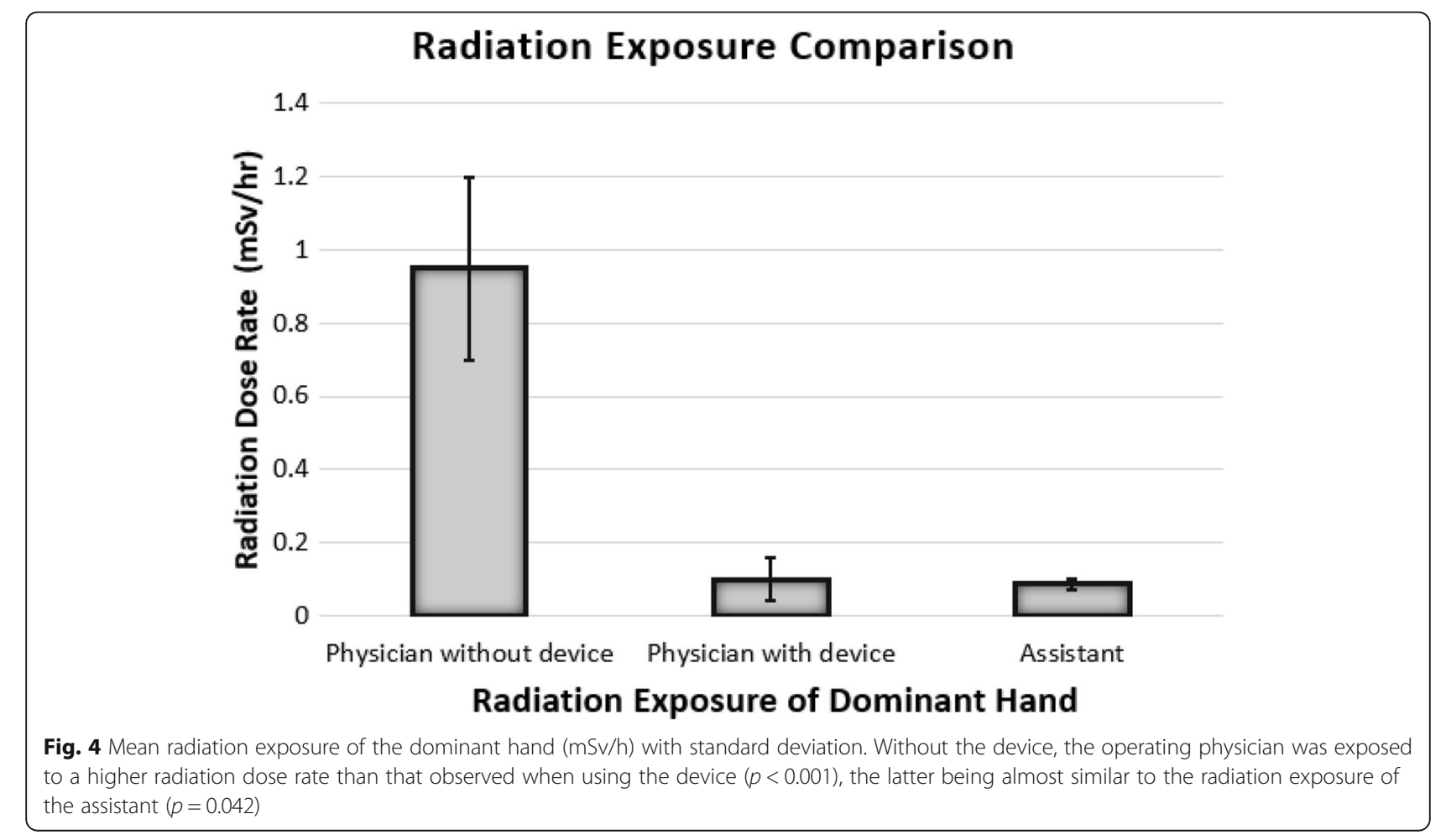


exposed to ionising radiation even after using different protective techniques. Robot-assisted vertebral body augmentation had reduced the radiation exposure for both the surgeon and medical staff [21]. A recent position paper on medical radiation of the European Society of Cardiology [22] urged technological innovations in the field to enhance the safety of the doctors working in the cardiac catheterisation laboratory. The robotic mechanism would be a way to the innovation.

To solve this problem, a passive robotic mechanism had been designed that helped the physician to stand and perform arterial puncturing away from the close vicinity of the $\mathrm{x}$-ray source. As a result, significant reduction of radiation happened for not only the hands of the operating physician but also for his other unprotected body parts.

One limitation of this study is the limited sample size. However, the reduction in radiation exposure associated with the use of the robotic device resulted to be significant. In addition, we should consider the passive limitation of the robotic mechanism: the physician had to operate it using his hands and could not operate remotely as in the case of active robotic mechanisms.

In conclusion, in this study on a swine model, the use of a passive robotic mechanism for arterial puncturing and guidewire insertion had significantly reduced radiation exposure for not only the hands but also for the overall body of the operating physician.

\section{Abbreviations}

DoF: Degree of freedom; SD: Standard deviation

\section{Acknowledgements}

This work was supported by the Technology Innovation Program (or Industrial Strategic Technology Development Program-Artificial intelligence bio-robot medical convergence project) (20001257, Artificial intelligence algorithm based vascular intervention robot system for reducing radiation exposure and achieving $0.5 \mathrm{~mm}$ accuracy) funded by the Ministry of Trade, Industry \& Energy (MOTIE, Korea), the Ministry of Health \& Welfare (MOHM), Ministry of Science and ICT (MSIT), Korea Evaluation Institute of Industrial Technology (KEIT), and the Technology Innovation Program (10052980, Development of microrobotic system for surgical treatment of chronic total occlusion) funded by the Ministry of Trade, Industry \& Energy, Korea, and performed by ICT based Medical Robotic Systems Team of Hanyang University, Department of Electronic Systems Engineering was supported by the BK21 Plus Program funded by National Research Foundation of Korea (NRF), and supported by WC300 R\&D Program (\$2482672) funded by the Small and Medium Business Administration, Korea.
\end{abstract}

\section{Funding}

This work was supported by the Technology Innovation Program (or Industrial Strategic Technology Development Program-Artificial intelligence bio-robot medical convergence project) (20001257, Artificial intelligence algorithm based vascular intervention robot system for reducing radiation exposure and achieving $0.5 \mathrm{~mm}$ accuracy) funded By the Ministry of Trade, Industry \& Energy (MOTIE, Korea), the Ministry of Health \& Welfare (MOHM), Ministry of Science and ICT (MSIT), Korea Evaluation Institute of Industrial Technology (KEIT), and the Technology Innovation Program (10052980, Development of microrobotic system for surgical treatment of chronic total occlusion) funded By the Ministry of Trade, Industry \& Energy, Korea, and performed by ICT based Medical Robotic Systems Team of Hanyang University, Department of Electronic Systems Engineering was supported by the BK21 Plus Program funded by National Research Foundation of Korea (NRF), and supported by WC300 R\&D Program (\$2482672) funded by the Small and Medium Business Administration, Korea.

\section{Availability of data and materials}

All data generated or analysed during this study are included in this published article and its supplementary files.

\section{Authors' contributions}

MUA and $\mathrm{CH}$ equally contributed to this paper. All authors read and approved the final manuscript. First author designed the robotic mechanism and collected the data. Second author performed the arterial puncturing procedures. Both first author and second author contributed in writing the manuscript. Corresponding author contributed in designing of the robot and writing of the manuscript.

\section{Ethics approval}

This study was approved by the Institutional Animal Care and Use Committee of Seoul National University Bundang Hospital and was performed in accordance with the Guide for the Care and Use of Laboratory Animals from the Institute of Laboratory Animals Resources. Consent to participate not applicable.

\section{Consent for publication}

Not applicable.

\section{Competing interests}

The authors declare that they have no competing interests.

\section{Publisher's Note}

Springer Nature remains neutral with regard to jurisdictional claims in published maps and institutional affiliations.

\section{Author details}

'Department of Mechatronics Engineering, Hanyang University, 55 Hanyangdeahak-ro, Sangnok-gu, Ansan 15588, Gyeonggi-do, South Korea. ${ }^{2}$ Department of Internal Medicine, Seoul National University Bundang Hospital, 82, Gumi-ro 173 Beon-gil, Bundang-gu, Seongnam 13620, Gyeonggi-do, South Korea. ${ }^{3}$ Department of Electronic Systems Engineering, Hanyang University, 55 Hanyangdeahak-ro, Sangnok-gu, Ansan 15588, Gyeonggi-do, South Korea.

Received: 14 March 2019 Accepted: 17 April 2019

Published online: 29 May 2019

\section{References}

1. Harstall R, Heini PF, Mini RL, Orler R (2005) Radiation exposure to the surgeon during fluoroscopically assisted percutaneous vertebroplasty: a prospective study. Spine (Phila Pa 1976) 30:1893-1898. https://doi.org/10. 1097/01.brs.0000174121.48306.16

2. Hellawell G, Mutch S, Thevendran G, Wells E, Morgan RJ (2005) Radiation exposure and the urologist: what are the risks? J Urol 174:948-952. https:// doi.org/10.1097/01.ju.0000170232.58930.8f

3. Miraglia R, Gerasia R, Maruzzelli L, D'Amico M, Luca A (2017) Radiation doses to operators performing transjugular intrahepatic portosystemic shunt using a flat-panel detector-based system and ultrasound guidance for portal vein targeting. Eur Radiol 27:1783-1786. https://doi.org/10.1007/s00330-016-4558-1

4. Efstathopoulos E, Pantos I, Andreou M et al (2011) Occupational radiation doses to the extremities and the eyes in interventional radiology and cardiology procedures. Br J Radiol 84:70-77. https://doi.org/10.1259/bjr/ 83222759

5. Kruger R, Faciszewski T (2003) Radiation dose reduction to medical staff during vertebroplasty: a review of techniques and methods to mitigate occupational dose. Spine (Phila Pa 1976) 28:1608-1613. https://doi.org/10. 1097/01.BRS.0000076832.18944.00

6. Kim KP, Miller DL, Berrington de Gonzalez A et al (2012) Occupational radiation doses to operators performing fluoroscopically-guided procedures. Health Phys 103:80. https://doi.org/10.1097/HP.0b013e31824dae76

7. Fossaceca R, Brambilla M, Guzzardi G et al (2012) The impact of radiological equipment on patient radiation exposure during endovascular aortic aneurysm repair. Eur Radiol 22:2424-2431. https:// doi.org/10.1007/s00330-012-2492-4

8. Paul J, Mbalisike EC, Vogl TJ (2013) Radiation dose to procedural personnel and patients from an X-ray volume imaging system. Eur Radiol 23:3262-3270. https://doi.org/10.1007/s00330-013-2939-2 
9. Fabritius G, Brix G, Nekolla E et al (2016) Cumulative radiation exposure from imaging procedures and associated lifetime cancer risk for patients with lymphoma. Sci Rep 6:35181. https://doi.org/10.1038/srep35181

10. Stavas JM, Smith TP, DeLong DM, Miller MJ, Suhocki PV, Newman GE (2006) Radiation hand exposure during restoration of flow to the thrombosed dialysis access graft. J Vasc Interv Radiol 17:1611-1617. https://doi.org/10. 1097/01.RVI.0000236842.49430.BD

11. Maeder M, Brunner-La Rocca HP, Peter $\mathrm{H}$ et al (2006) Impact of a lead glass screen on scatter radiation to eyes and hands in interventional cardiologists. Catheter Cardiovasc Interv 67:18-23. https://doi.org/10.1002/ccd.20457

12. Häusler U, Czarwinski R, Brix G (2009) Radiation exposure of medical staff from interventional x-ray procedures: a multicentre study. Eur Radiol 19:2000-2008. https://doi.org/10.1007/s00330-009-1388-4

13. Vosbikian MM, llyas AM, Watson DD, Leinberry CF (2014) Radiation exposure to hand surgeons' hands: a practical comparison of large and mini C-arm fluoroscopy. J. Hand Surg Am 39:1805-1809. https://doi.org/10.1016/j.jhsa. 2014.06.133

14. Whitby M, Martin C (2005) A study of the distribution of dose across the hands of interventional radiologists and cardiologists. Br J Radiol 78:219229. https://doi.org/10.1259/bjr/12209589

15. Wrixon AD (2008) New ICRP recommendations. J Radiol Prot 28:161 https:// doi.org/10.1088/0952-4746/28/2/R02

16. Institute of Laboratory Animal Resources (U.S.) Committee on Care and Use of Laboratory Animals, National Institutes of Health (U.S.) Division of Research Resources (1985) Guide for the care and use of laboratory animals. U.S. Dept. of Health and Human Services, Public Health Service, National Insititutes of Health, Bethesda

17. Prasad A, Compton PA, Prasad A et al (2008) Incidence and treatment of arterial access dissections occurring during cardiac catheterization. J Interv Cardiol 21:61-66. https://doi.org/10.1111/j.1540-8183.2007.00309.x

18. Narain AS, Hijji FY, Yom KH, Kudaravalli KT, Haws BE, Singh K (2017) Radiation exposure and reduction in the operating room: perspectives and future directions in spine surgery. World J Orthop 8:524. https://doi.org/10. 5312/wjo.v8.i7.524

19. Meisinger QC, Stahl CM, Andre MP, Kinney TB, Newton IG (2016) Radiation protection for the fluoroscopy operator and staff. Am J Roentgenol 207:745-754. https://doi.org/10.5312/wjo.v8.i7524

20. Werner GS, Glaser P, Coenen A et al (2017) Reduction of radiation exposure during complex interventions for chronic total coronary occlusions: implementing low dose radiation protocols without affecting procedural success rates. Catheter Cardiovasc Interv 89:1005-1012 https://doi.org/10. 1002/ccd.26886

21. Barzilay Y, Schroeder JE, Hiller N et al (2014) Robot-assisted vertebral body augmentation: a radiation reduction tool. Spine (Phila Pa 1976) 39:153-157. https://doi.org/10.1097/BRS.0000000000000100

22. Picano E, Vañó $\mathrm{E}$, Rehani $\mathrm{MM}$ et al (2014) The appropriate and justified use of medical radiation in cardiovascular imaging: a position document of the ESC associations of cardiovascular imaging, percutaneous cardiovascular interventions and electrophysiology. Eur Heart J 35:665-672. https://doi.org/ 10.1093/eurheartj/eht394

\section{Submit your manuscript to a SpringerOpen ${ }^{\circ}$ journal and benefit from:}

- Convenient online submission

- Rigorous peer review

- Open access: articles freely available online

High visibility within the field

- Retaining the copyright to your article

Submit your next manuscript at $\boldsymbol{\nabla}$ springeropen.com 